\title{
O efeito de estímulos morais e éticos como resposta ao problema do risco moral: uma verificação experimental em grupos de estudantes
}

\section{de Ciências Contábeis}

\author{
José Alves Dantas \\ Doutor em Contabilidade - UnB/UFPB/UFRN \\ Professor da Universidade de Brasília (UnB) \\ josealvesdantas@gmail.com
}

\author{
José Marilson Martins Dantas \\ Doutorando \\ Programa Multiinstitucional e Inter-Regional de \\ Pós-Graduação em Ciências Contábeis - UnB/UFPB/UFRN \\ Professor da Universidade Federal da Paraíba (UFPB) \\ marilsondantas@gmail.com
}

\author{
César Augusto Tibúrcio Silva \\ Doutor em Contabilidade pela USP \\ Programa Multiinstitucional e Inter-Regional de \\ Pós-Graduação em Ciências Contábeis - UnB/UFPB/UFRN \\ cesartiburcio@unb.br
}

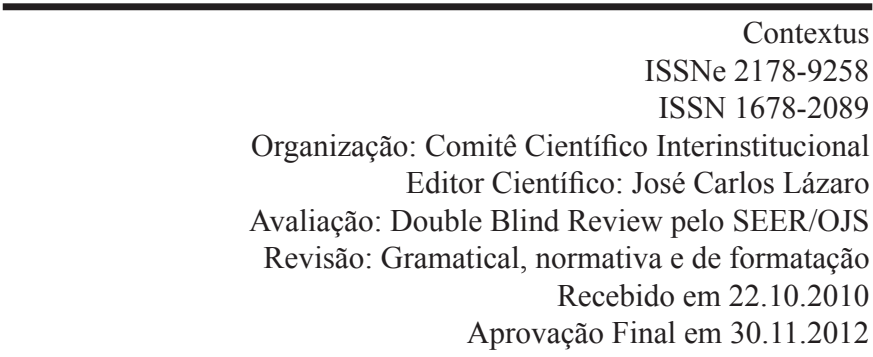

Contextus

ISSNe 2178-9258

ISSN 1678-2089

Organização: Comitê Científico Interinstitucional

Editor Científico: José Carlos Lázaro Avaliação: Double Blind Review pelo SEER/OJS Recebido em 22.10.2010 Aprovação Final em 30.11.2012

\section{RESUMO:}

O estudo teve por objetivo verificar, considerando os preceitos do modelo básico principal-agente, se estímulos morais contribuem ou não para reduzir a probabilidade de materialização do risco moral na profissão contábil, representado pelos eventuais desvios éticos de seus integrantes. Foi examinado, por meio de experimento, se os estudantes de Ciências Contábeis reagem a estímulos morais, como a leitura do "juramento" prestado pelos formandos, apresentando um comportamento mais ético que os alunos não submetidos a esse estímulo. Os resultados, obtidos em uma amostra de 401 alunos de duas universidades federais, de uma universidade privada e de um centro universitário, corroboraram as premissas da pesquisa, rejeitando-se a hipótese nula de que esse estímulo não influencia no padrão de respostas. As conclusões ficam mais robustas quando são retirados os efeitos dos valores extremos, os outliers. Testes realizados em relação aos segmentos específicos revelaram que esse efeito foi mais evidente nos estudantes de instituições privadas, do sexo masculino, com idade superior a vinte e cinco anos e que estão cursando até o quarto semestre.

Palavras-chave: Experimento. Risco Moral. Estímulo Moral. Comportamento. Ética. Contadores.

\section{ABSTRACT:}

This study aimed to determine, based on the precepts of the model basic principal-agent, if moral incentives contribute or not to reduce the likelihood of realization of moral hazard in the accounting profession, represented by any ethical deviations of its members. It tried to examine, through an experiment, if the accounting students react the moral stimulations, the reading of the "oath" provided by the graduates, with a more ethical behavior than the students who had not been submitted to this stimulus. The results, obtained in a sample of 401 students from two public universities, a private university and a university center, corroborated the assumptions of the research, rejecting the null hypothesis of that this stimulus does not influence in the pattern of responses. The findings are more robust when they are removed from the effects of the outliers. Tests performed on specific segments showed that this effect was more evident in the students of private institutions, male, aged twenty-five years and are attending a course until fourth semester.

Keywords: Experiment. Moral Hazard. Moral Stimulation. Behavior. Ethics. Accountants. 


\section{INTRODUÇÃO}

Uma das questões que invariavelmente tem sido objeto de discussões no âmbito da profissão contábil é o comportamento ético dos profissionais da área. Isso adquire ainda mais relevância nos momentos em que surgem evidências de participação de contadores e auditores em escândalos corporativos, como os ocorridos no início dos anos 2000, com os casos Enron, WorldCom, Tyco, Parmalat, entre outros, ou nos recorrentes casos de sonegação fiscal divulgados no Brasil.

Conceitualmente, esse tipo de situação pode ser definido - a partir do modelo principal-agente, consolidado na literatura que trata da assimetria de informação e teoria da agência - como a materialização do risco moral, que consiste na possibilidade de os agentes não atuarem de acordo com os interesses do principal. No caso, o principal poderia ser definido como a própria profissão regulamentada, que estabelece padrões de comportamento a serem seguidos pelos profissionais, que seriam os agentes.

A resposta mais comumente adotada para fazer frente a esse tipo de problema tem sido o reforço do aparato legal e normativo, procurando consolidar os limites da atuação profissional, como forma de desencorajar o comportamento inapropriado dos contadores e auditores, o que afeta a imagem da profissão como um todo.

Não obstante o consenso quanto à relevância do estabelecimento de leis e normas que busquem mitigar o risco de comportamento aético desses profissionais, pouco se tem pesquisado sobre os reais efeitos dessa estrutura legal e normativa na conduta de contadores e auditores, muito menos na formação dos futuros profissionais - os estudantes de Ciências Contábeis. Nas áreas de finanças e de contabilidade, as pesquisas que procuram avaliar o comportamento dos agentes envolvidos nas tomadas de decisões financeiras e de reconhecimento dos eventos econômicos têm sido denominadas de finanças comportamentais e contabilidade comportamental, respectivamente.

Nesse contexto, o presente estudo tem por objetivo verificar, tendo por base os preceitos conceituais do modelo básico principal-agente, se estímulos morais e éticos contribuem ou não para reduzir a probabilidade de materialização do risco moral.

A pesquisa tem inspiração no trabalho de Ariely (2008), quanto ao proceder metodológico, e em Stevens e Thavarajan (2010), quanto à premissa de uma solução moral para o problema do risco moral. Ao testar a forma como os estudantes respondem ao estímulo moral, tem como referência a condição de que o comportamento ético do futuro profissional contábil pode ser influenciado por reforço em sua formação moral enquanto estudante.

De acordo com o resultado do experimento, podese concluir ou não pela necessidade de se reforçarem disciplinas que trabalhem os aspectos morais e éticos na formação do profissional contador.

\section{O MODELO PRINCIPAL-AGENTE E O RIS- CO MORAL}

Uma das questões mais estudadas na moderna teoria das finanças é a hipótese de eficiência de mercado, que se baseia na premissa de que os preços refletem todas as informações relevantes disponíveis sobre um determinado ativo em um mercado eficiente, tendo como paradigma dominante a presunção que os tomadores de decisão são considerados racionais e maximizadores de utilidades.

Em sentido oposto aos conceitos tradicionais de racionalidade imposta pela teoria moderna das finanças, emergem as pesquisas em finanças comportamentais. Segundo Macedo Júnior et al. (2007), diversos pesquisadores como Miller, Galanter e Pribam (1960), Newell, Sahw e Simon (1958), a partir da década de 50, insatisfeitos com a explicação do processo de racionalidade para tomada de decisão, observaram, nas suas pesquisas, que a premissa de racionalidade era rompida no processo de tomada de decisão em vários cenários.

Kuhn (1975), ao abordar a questão relacionada à evolução da ciência, especialmente sobre a quebra de paradigma quando do desenvolvimento de uma nova teoria, destaca que nunca ou quase nunca é um mero incremento ao 
que já é conhecido, por mais particular que seja seu âmbito de aplicação. Assim, um novo paradigma requer a reconstrução da teoria precedente e a reavaliação dos fatos anteriores.

Nesse contexto, as finanças comportamentais têm despertado, nas últimas décadas, o interesse dos pesquisadores, enfatizando o estudo do comportamento aplicado às finanças, especialmente dos estudos advindos da psicologia cognitiva.

Diversos pesquisadores definem o escopo das finanças comportamentais, podendo ser destacada a definição de Shleifer (apud KIMURA, 2003), onde o autor afirma que elas representam o estudo potencial de falha humana em mercados competitivos, ao abordar os eventuais impactos em variáveis financeiras quando investidores racionais e irracionais interagem entre si.

Lima (2003), por sua vez, citando a definição sob a visão de Olsen, sustenta que as finanças comportamentais têm o propósito de entender e predizer os processos de decisão psicológicos que implicam na sistemática dos mercados, e não de definir o comportamento racional ou irracional. $\mathrm{Na}$ mesma linha de entendimento, Lintner (apud SOBREIRA, 2007) coloca as finanças comportamentais como o estudo da maneira pela qual os humanos interpretam as informações para decidir sobre investimentos e agem diante delas.

Entender o processo de tomada de decisão leva a compreender o ambiente em que os atores protagonizam a ação e consequentemente aos preceitos da teoria da agência. Desse modo, de acordo com Lambert (2007), nos modelos mais simples da teoria da agência, a organização está reduzida a dois atores: o principal e o agente. Nesse caso, a função do principal é a oferta de capital, a assunção de riscos e a formulação de incentivos, enquanto o papel do agente consiste em tomar decisões em nome do principal, bem como buscar a minimização do risco, sendo esta última uma atribuição frequentemente assumida como uma preocupação secundária.

De acordo com o que expõe Eisenhardt (1989), a teoria da agência tem o seu desenvolvimento baseado em duas linhas de atuação: a linha denominada positivista e a do principal-agente. As duas linhas de pesquisa têm muitos aspectos em comum, divergindo com relação à abordagem. Segundo o autor, a abordagem dos pesquisadores positivistas tem se preocupado em identificar situações em que o principal e o agente podem ter objetivos conflitantes e, em seguida, descrever os mecanismos de governança que limitem o comportamento autônomo do agente.

Ainda conforme Eisenhardt (1989), a segunda abordagem pode ser definida como a situação em que o foco do principal-agente é determinar o melhor contrato, comportamento versus resultado, entre o principal e o agente. Dessa forma, o modelo simples assume o conflito entre o objetivo do principal e o do agente, sendo este modelo facilmente medido pelo resultado, e onde o agente é mais avesso ao risco do que o principal.

Dentro desse princípio, a teoria da agência pode ser exposta, de maneira geral, de acordo com o quadro abaixo:

\section{Quadro1 - Aspectos centrais da Teoria da Agência}

\begin{tabular}{|l|l|}
\hline \multicolumn{1}{|c|}{ Aspectos Centrais } & \multicolumn{1}{c|}{ Exposição } \\
\hline $\begin{array}{l}\text { Ideia Principal da Teoria da } \\
\text { Agência }\end{array}$ & $\begin{array}{l}\text { As relações entre o principal e agente deve se refletir na organização } \\
\text { eficiente das informações e do risco que pode suportar. }\end{array}$ \\
\hline Unidade de Análise & Contrato entre o principal e o agente. \\
\hline Pressupostos Individuais & $\begin{array}{l}\text { Interesses particulares; } \\
\text { Racionalidade restrita; } \\
\text { Aversão ao risco. }\end{array}$ \\
\hline Pressupostos Organizacionais & $\begin{array}{l}\text { Conflitos parciais entre os participantes; } \\
\text { Eficiência como criterio de efetividade; } \\
\text { Assimetria de informações entre o principal e o agente. }\end{array}$ \\
\hline Pressuposto Informacional & Informação como uma commodity passível de ser comprada. \\
\hline Problemas de Restrições & $\begin{array}{l}\text { Agência (risco moral e seleção adversa); } \\
\text { Risco partilhado. }\end{array}$ \\
\hline Problema Dominante & $\begin{array}{l}\text { Relacionamentos em que o principal e o agente têm objetivos que } \\
\text { diferem parcialmente e preferências diferentes pelo risco. }\end{array}$ \\
\hline
\end{tabular}

Fonte: Adaptado de Eisenhardt (1989, p. 58).

Ao destacarem mais especificamente a caracterização de um relacionamento de agência, Jensen e Merckling (1976) e Macieira (2006) afirmam que ele é definido como uma espécie de contrato (sistema de compensação) sob o qual pessoas (principal) encarregam outras (agente) para executar atividades de seu interesse, numa espécie de comportamento cooperativo, ressaltando-se, porém, que esses indivíduos não são sócios e nem estão legalmente em situação de igualdade. 
A teoria da agência tem como uma das restrições o risco moral no desenvolvimento do contrato entre o principal e o agente. Segundo Holmstron (1979), uma forma de mitigar o risco moral é investir recursos em ações de acompanhamento e utilizar essa informação no contrato, no que poderia ser definido como um remédio natural para o problema. O próprio autor ressalta, porém, que esse acompanhamento completo pode ser possível em situações simples. Em outro tipo de situação, uma solução pode ser obtida pelo emprego de um contrato que penalize o comportamento disfuncional, o que implica na partilha ótima do risco. Geralmente, porém, segundo o autor, a plena observação das ações é impossível ou proibitivamente cara.

Stevens e Thevaranjan (2010) apresentam uma outra sugestão para a resolução do risco moral, que seria uma solução moral. Destacam os autores que o modelo tradicional principal-agente, que concentra sua solução basicamente no "incentivo", ignora a sensibilidade moral do agente, o que resulta no aumento potencial do custo para o capital, tendo em vista que cada solução apresenta uma hipótese extrema que impede a possibilidade de outra solução.

A comparação entre o modelo principal-agente com a sensibilidade moral e o modelo tradicional, enfatizando a proposta de uma possibilidade de mitigação do risco moral, é apresentada por Stevens e Thevaranjan (2010) conforme a Figura 1 a seguir:

Figura1 - Comparação dos eventos no modelo principal-agente com sensibilidade moral e o modelo principal-agente tradicional

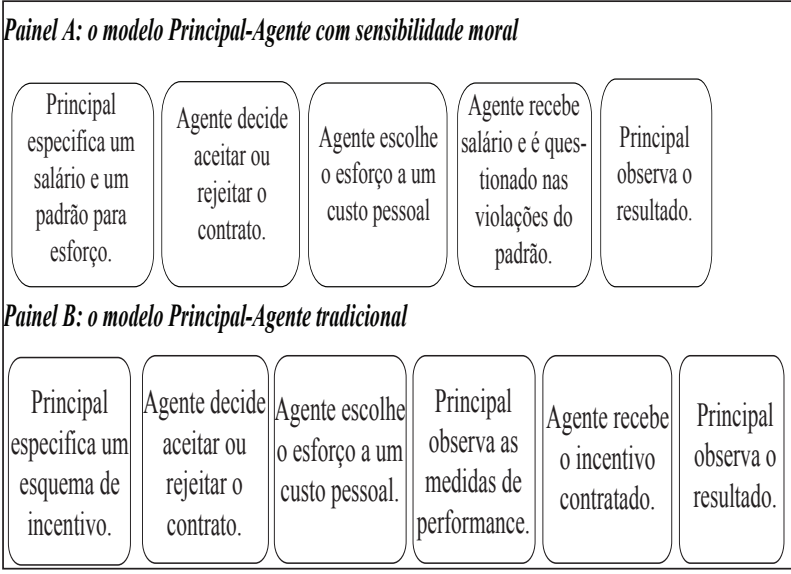

Fonte: Baseada em Stevens e Thevaranjan (2010)

\section{PROCEDIMENTOS METODOLÓGICOS}

Seguindo o modelo básico principal-agente, que dá sustentação teórica às reflexões sobre risco moral, e inspirada em metodologia aplicada por Ariely (2008), a pesquisa consistiu em um experimento aplicado a grupos de alunos de Ciências Contábeis, durante o mês de maio de 2009, em que o principal (os pesquisadores) propõe aos agentes (os alunos pesquisados), a realização de um teste com quinze perguntas versando sobre Contabilidade Geral, oferecendo uma recompensa, sob a forma de chocolates, de acordo com o rendimento obtido pelo participante ${ }^{1}$.

De acordo com essa construção metodológica, a configuração do risco moral decorre da possibilidade de o agente não se esforçar adequadamente para alcançar um bom desempenho ou fraudar o resultado a ser apresentado. Isso porque, na realização do teste, os alunos pesquisados não precisaram comprovar o número de acertos (não devolveram o caderno de questões), apenas indicaram o número de acertos, tendo por base o gabarito disponibilizado após decorrido o tempo limite de quinze minutos para a resposta das questões. Tanto o caderno de questões quanto o gabarito foram destruídos pelos próprios pesquisados e jogados no lixo.

Como foi devolvida apenas a folha de respostas, em que consta o número de questões declaradas como corretas, sem qualquer tipo de verificação pelo pesquisador, o agente teve condições, se o quisesse, de modificar o número de respostas certas. O fato de a remuneração a quantidade de chocolates - estar vinculada ao grau de acerto foi um estímulo para esse tipo de fraude.

$\mathrm{Na}$ realização do experimento, os estudantes foram distribuídos em dois grupos, de acordo com o tipo da folha de respostas que receberam:

- no primeiro grupo, os pesquisados receberam uma folha de respostas em que consta, além do campo para a

1 - (i) de uma a quatro questões certas - um chocolate; (ii) de cinco a oito questões certas - dois chocolates; (iii) de nove a doze questões certas - três chocolates; (iv) de treze a quatorze questões - quatro chocolates; (v) quinze questões certas - cinco chocolates. 
indicação do número de respostas corretas e de algumas variáveis de controle (gênero, idade e semestre que está cursando) que permitam o cruzamento de análises, um texto sobre metrópoles brasileiras, que é neutro em relação aos propósitos de se avaliar o comportamento dos agentes em relação ao risco moral;

- no segundo grupo, a folha de respostas continha, além do campo do número de acertos e das variáveis de controle, a transcrição do juramento realizado pelos formandos em Ciências Contábeis, destacando os aspectos zelo, diligência, honestidade, verdade, justiça, entre outros.

Nos dois casos, foi solicitada do respondente a elaboração de uma frase que sintetizasse o texto que constava na folha de respostas - sobre as metrópoles ou sobre o juramento - como forma de se obter a particularmente a segurança de que a leitura do juramento, no caso do segundo grupo, fosse realizada. A premissa considerada é de que os alunos que recebessem o segundo tipo de folha de resposta contavam com um estímulo moral e ético para informar corretamente o número de acertos.

Para a prevenção dos riscos de eventuais contaminações do estudo em razão de diferenças de conhecimento entre os alunos pesquisados - os agentes -, foi estabelecido o critério de que em cada turma submetida aos questionários os alunos seriam divididos, sem que eles tivessem ciência disso, em proporções iguais e de forma aleatória entre os dois tipos de folha de resposta - com e sem estímulo moral - distribuídos intercaladamente.

\subsection{Definição das hipóteses de pesquisa}

Considerando-se a metodologia de aplicação da pesquisa, com a divisão em proporções iguais e de forma aleatória dos dois tipos de folha de respostas - com e sem estímulo moral - distribuídos intercaladamente, é esperado que em uma situação de normalidade - sem qualquer estímulo o resultado médio apresentado pelos dois grupos deva ser equivalente.

Confirmando-se os estudos realizados por Ariely (2008), espera-se, porém, que os alunos que receberam o estímulo moral - o juramento -, sejam menos propensos a fraudar o número de respostas corretas. Com isso, a média alcançada por esses alunos seria inferior à informada pelos que não receberam qualquer tipo de estímulo moral para agir corretamente.

Nesse contexto, as hipóteses testadas no experimento são $H_{0}$ : 0 estímulo moral, representado pelo juramento realizado pelos formandos em Ciências Contábeis, não influencia no padrão de respostas por parte dos pesquisados, resultando em nivel de acertos estatisticamente equivalentes entre os dois grupos.

$H_{1}$ : 0 estimulo moral, representado pelo juramento realizado pelos formandos em Ciências Contábeis, influencia no padrão de respostas por parte dos pesquisados, resultando em nivel de acertos inferior ao do grupo que não recebeu esse estímulo.

\subsection{Definição do Modelo de Análise}

A realização dos testes empíricos considera a especificação de uma regressão linear, a partir da qual seja possível se concluir sobre a relação entre o nível de acertos declarados pelos respondentes e o estímulo moral representado pelo "juramento".

Nesse sentido, a análise dos dados tem como referência o modelo a seguir descrito, elaborado a partir dos propósitos do estudo e das hipóteses de pesquisa formuladas:

$$
\text { ACERTO }_{i}=\beta_{0}+\beta_{1} \text { ESTÍMULO }_{i}+u_{i}
$$

onde: $A C E R T O_{i}$ é o nível de acerto declarado pelo aluno $i$; ESTÍMULO ${ }_{i}$ representa a existência do estímulo moral (1 para o aluno $i$ que leu o "juramento" e 0 para o aluno $i$ que leu o texto neutro); $\beta_{0}$ é o coeficiente do intercepto, quando a variável independente for igual a zero; $\beta_{1}$ é o coeficiente de inclinação da regressão, relacionado com a variável dependente - o estímulo moral; e $u_{i}$ é o termo de perturbação ou erro, assumindo a normalidade dos resíduos, ou seja, $\sim \mathrm{N}\left(0, \sigma^{2}\right)$.

Tendo em vista a formulação das hipóteses nula e alternativa, a rejeição de $\mathrm{H}_{0}$ fica condicionada à verificação de que o coeficiente da variável seja estatisticamente relevante e apresente sinal negativo, ou seja, o estímulo contribui para reduzir o nível de acertos declarado pelos respondentes. Ademais, tendo em vista os termos da formulação da hipótese alternativa, $\mathrm{H}_{1}$, em que avalia apenas a condição de o grupo que recebeu o estímulo apresentar um resultado médio inferior ao que recebeu o texto "neutro", os testes estatísticos são do tipo unicaudal. 


\subsection{Amostra}

O experimento envolveu a participação de 401 alunos de Ciências Contábeis da Universidade Federal da Paraíba (UFPB), da Universidade de Brasília (UnB), da Universidade Católica de Brasília (UCB) e do Centro Universitário Unieuro, em Brasília, durante o mês de maio de 2009, em duas etapas: (i) num primeiro momento, 287 alunos participaram da pesquisa, possibilitando a apuração das impressões sobre as hipóteses de pesquisa; (ii) num segundo momento, considerando a necessidade de testes adicionais para verificação de possibilidades de níveis diferentes de respostas em função de modificação no padrão de premiação por acerto, conforme descrito na seção 4.7, participaram outros 114 alunos.

As estatísticas descritivas que caracterizam os respondentes, considerando o tipo de instituição, o gênero, a faixa etária e o estágio dos alunos no curso, estão demonstradas na tabela a seguir:

Tabela 1 - Caracterização dos Respondentes Estatísticas Descritivas

\begin{tabular}{|c|c|c|c|}
\hline Características & Descrição & Quantidade & Percentual \\
\hline \multirow{2}{*}{ Por tipo de instituição } & Pública & 243 & $60.60 \%$ \\
\hline & Privada & 158 & $39.40 \%$ \\
\hline \multirow{2}{*}{ Por tipo de instituição } & Masculino & 224 & $55.86 \%$ \\
\hline & Feminino & 177 & $44.14 \%$ \\
\hline \multirow{4}{*}{ Por faixa etária } & Até 20 anos & 138 & $34.41 \%$ \\
\hline & De 21 a 24 anos & 128 & $31.92 \%$ \\
\hline & De 25 a 30 anos & 76 & $18.95 \%$ \\
\hline & Acima de 30 anos & 59 & $14.71 \%$ \\
\hline \multirow{3}{*}{ Por estágio no curso } & Até $4^{\circ} \mathrm{sem}$. & 132 & $32.92 \%$ \\
\hline & $5^{0}$ e $6^{0}$ sem. & 206 & $51.37 \%$ \\
\hline & A partir do $7^{\circ}$ sem. & 63 & $15.71 \%$ \\
\hline \multicolumn{2}{|c|}{ Total } & 401 & $100.00 \%$ \\
\hline
\end{tabular}

Como limitação, há de se ressaltar o fato de que a seleção das turmas que participaram da pesquisa dependeu fundamentalmente da oportunidade de acesso que os pesquisadores tiveram, não se observando o rigor estatístico de aleatoriedade da amostra, o que compromete a formulação de inferências para o conjunto dos alunos de Ciências Contábeis do País, de uma região ou mesmo das cidades pesquisadas.

\section{APRESENTAÇÃO E ANÁLISE DOS RESUL- TADOS}

Nas seções a seguir são apresentadas as análises dos resultados apurados, considerando-se o conjunto dos respondentes e as variáveis de controle - tipo de instituição, gênero, idade e estágio do aluno no curso.

Além disso, outro procedimento adotado para avaliar a robustez dos resultados consiste em analisar o impacto dos valores extremos. A avaliação do impacto dos outliers na determinação do efeito de estímulos morais como resposta ao problema do risco moral se justifica em função de que, em alguns casos, a dimensão dos valores extremos pode ser determinante na definição do comportamento médio do conjunto, o que poderia resultar em conclusões enviesadas sobre o experimento, conforme descreve Brooks (2008). Para a prevenção desse problema, a amostra original é depurada com a exclusão, em cada grupo, dos elementos da amostra cujos acertos se distanciam mais de dois desvios padrões em relação à média, o que reduziu o número de elementos para 276, tendo metade deles respondido ao questionário com o estímulo moral e a outra metade respondido sem esse estímulo.

Também para avaliar a robustez dos resultados econométricos, são realizados testes de verificação de raízes unitárias - para confirmar que as regressões não são espúrias - e de normalidade, de autocorrelação e de heterocedasticidade nos resíduos - condições para se concluir que as regressões podem ser consideradas como "melhores estimadores lineares não viesados".

\subsection{Resultados do Conjunto da Amostra}

Tendo por base o modelo (3.1) de regressão linear, destacado anteriormente, foram realizados os testes para verificação da significância estatística da variável para explicar . Nesses testes, consideraram-se as bases de dados completa e com exclusão dos outliers, apresentando os seguintes resultados: 
Tabela 2 - Resumo dos Testes do modelo (3.1) - Conjunto da Amostra

\begin{tabular}{|c|c|c|c|c|c|}
\hline \multicolumn{6}{|c|}{ Varinarel dependente" ACERTOS } \\
\hline $\begin{array}{l}\text { Identificacàa do } \\
\text { segmento da da amostra }\end{array}$ & $\begin{array}{l}\text { Tamanhlo } \\
\text { amostia }\end{array}$ & $\begin{array}{l}\text { Variàivel } \\
\text { independente }\end{array}$ & Coeficient & Estatisticat & $p-12$ \\
\hline \multirow{2}{*}{ Amostra completa } & \multirow{2}{*}{287} & C & 7,5833 & 40,7977 & 0,0000 \\
\hline & & ESTIMULO & $.0,3316$ & $.1,5992$ & 0,105 \\
\hline \multirow{2}{*}{ amostita Excluindo outliers } & \multirow{2}{*}{276} & C & 7,7898 & 47,121 & 0,0000 \\
\hline & & ESTIMULO & $.0,4927$ & $.1,9999$ & 0,0232 \\
\hline
\end{tabular}

Os resultados demonstram que, nos dois casos, o sinal do coeficiente da variável independente ESTÍMULO $i$ é negativo, coerente com as premissas da pesquisa. Quanto à significância estatística, os dados do $p$-valor evidenciam que, considerando todos os dados da amostra, a hipótese nula só é rejeitada com um nível de confiança de $89,55 \%$, enquanto com a exclusão dos outliers a $\mathrm{H}_{0}$ é rejeitada, confirmando-se a hipótese da pesquisa, com um nível de confiança de 97,68\%.

Em resumo, as evidências confirmam a premissa de que o estímulo moral, representado pela leitura do juramento realizado pelos formandos em Ciências Contábeis, influencia no padrão de respostas por parte dos pesquisados, notadamente quando é promovida a depuração dos dados, com a eliminação dos efeitos dos valores extremos.

Os dados das estatísticas descritivas de cada grupo, com e sem estímulo, em cada um dos métodos de análise - amostra completa e excluindo os outliers - estão demonstrados na Tabela 2, evidenciando que a média de acertos declarados pelo grupo que recebeu o estímulo é menor que a do grupo que leu o texto "neutro".
Tabela 3 - Estatísticas Descritivas - Resultados do Conjunto da Amostra Pesquisada

\begin{tabular}{|c|c|c|c|c|}
\hline \multirow{2}{*}{ Estatística } & \multicolumn{2}{|c|}{ Amostra Completa } & \multicolumn{2}{|c|}{ Excluindo Outliers } \\
\hline & Com estímulo & Sem estímulo & Com estímulo & Sem estímulo \\
\hline $\mathrm{N}^{0}$ elementos & 143 & 144 & 138 & 138 \\
\hline Total amostra & \multicolumn{2}{|c|}{287} & \multicolumn{2}{|c|}{276} \\
\hline Média & 7,25 & 7,58 & 7,30 & 7,79 \\
\hline Moda & 7,00 & 8,00 & 7,00 & 8,00 \\
\hline Mediana & 7,00 & 8,00 & 7,00 & 8,00 \\
\hline Máximo & 12,00 & 12,00 & 11,00 & 12,00 \\
\hline Mínimo & 2,00 & 2,00 & 3,00 & 4,00 \\
\hline Desvio padrão & 2,19 & 2,26 & 2,02 & 2,08 \\
\hline Variância & 4.82 & 5.13 & 4.06 & 4.31 \\
\hline
\end{tabular}

Como forma de verificar a robustez dos resultados encontrados, foram realizados testes para verificar se os dados utilizados nos exames são estacionários, bem como se os resíduos da regressão são normalmente distribuídos, não são autocorrelacionados e não apresentam heterocedasticidade. Os resultados desses testes estão consolidados na Tabela 4, a seguir:

Tabela 4 - Resumo dos Testes de Robustez dos Resul-

\begin{tabular}{|c|c|c|c|c|}
\hline Objetivo & Teste & Estatistica & p-valor & Conclusão \\
\hline $\begin{array}{l}\text { Raizes Unitárias- } \\
\text { variável ACERTO }\end{array}$ & $\mathrm{ADF}$ & -17.59814 & 0.0000 & Não há ráizes unitárias na série. \\
\hline $\begin{array}{l}\text { Raizes Unitárias - } \\
\text { variável ESṪMULO }\end{array}$ & $\mathrm{ADF}$ & -15.49315 & 0.0000 & Não há raízes unitárias naỉé \\
\hline $\begin{array}{l}\text { Autocorrelação nos } \\
\text { resíduos }\end{array}$ & Durbin-Watson & -2.075285 & & $\begin{array}{l}\text { Não há evidências de } \\
\text { autocorrelação. }\end{array}$ \\
\hline $\begin{array}{l}\text { Heterocedasticidade } \\
\text { nos resíduos }\end{array}$ & White & 0.182758 & 0.6694 & $\begin{array}{l}\text { Não rejeita } \mathrm{H}_{0} \text {, porque não há } \\
\text { heterocedasticidade. }\end{array}$ \\
\hline $\begin{array}{l}\text { Normalidade nos } \\
\text { resíduos }\end{array}$ & Jarque-Bera & 6.285288 & 0.0431 & $\begin{array}{l}\text { Hode normalidade não é rejeitad } \\
\text { com nivel de confianca de } 96 \% \text {. }\end{array}$ \\
\hline
\end{tabular}

Os resultados permitem concluir que não há raízes unitárias nas séries de dados utilizadas nos testes, o que permite afirmar que as regressões não são espúrias. Além do mais, o fato de os resíduos serem normalmente distribuídos, não serem autocorrelacionados e serem homocedásticos são requisitos para se apontar que os regressores podem ser considerados como "melhores estimadores lineares não viesados". Os resultados de todos esses testes, portanto, são elementos que reforçam a robustez dos resultados empíricos encontrados.

Destacados os resultados no conjunto da amostra, nas seções seguintes são analisados os efeitos do estímulo por variáveis específicas - por tipo de instituição, por gênero, por faixa etária e por estágio do aluno no curso - no sentido de concluir se o efeito do estímulo moral se 
manifesta de forma diferente entre nichos específicos da amostra pesquisada.

\subsection{Resultados por Tipo de Instituição}

Entre as variáveis de controle utilizadas para verificar situações específicas de respostas ao estímulo moral, uma delas foi o tipo de instituição, segregando-se os respondentes entre os alunos de instituições públicas e de instituições privadas. Os resultados dos testes por tipo de instituição também foram apurados de acordo com o grupo (com e sem estímulo) e com os métodos de análise (amostra completa e excluindo os outliers) e estão sintetizados na Tabela 5, a seguir:

Tabela 5 - Resumo dos Testes do modelo (3.1) - Por Tipo de Instituição

\begin{tabular}{|c|c|c|c|c|c|}
\hline \multicolumn{6}{|c|}{ Variável dependente: ACERTOS } \\
\hline \multicolumn{2}{|c|}{$\begin{array}{l}\text { Identificacão do } \\
\text { segmento da amostra }\end{array}$} & $\begin{array}{l}\text { Tamanho } \\
\text { amostra }\end{array}$ & $\begin{array}{l}\text { Varíavel } \\
\text { independente }\end{array}$ & Coeficiente Estatisticat & p-valor \\
\hline \multirow{4}{*}{$\begin{array}{l}\text { Instituicãa a } \\
\text { pubblica }\end{array}$} & \multirow{2}{*}{ Amostra completa } & \multirow{2}{*}{158} & $c$ & $\begin{array}{ll}7,7590 & 35,3875\end{array}$ & 0,0000 \\
\hline & & & ESTíMULO & $0,0785 \quad 0,2516$ & 0,4009 \\
\hline & \multirow{2}{*}{ Excluindooutliers } & \multirow{2}{*}{155} & $c$ & $7,9221 \quad 36,9219$ & 0,0000 \\
\hline & & & ESTíMULO & $-0,0887 \quad-0,2934$ & 0,3848 \\
\hline \multirow{4}{*}{$\begin{array}{l}\text { Instituicãa } \\
\text { privada }\end{array}$} & \multirow{2}{*}{ Amostra completa } & \multirow{2}{*}{129} & $c$ & $\begin{array}{ll}7,2576 & 24,7717\end{array}$ & 0,0000 \\
\hline & & & ESTíMULO & $-0,8766 \quad-2,0910$ & 0,0192 \\
\hline & \multirow{2}{*}{ Excluindoutliers } & \multirow{2}{*}{121} & 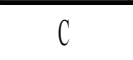 & $\begin{array}{ll}7,6229 & 27,6753\end{array}$ & 0,0000 \\
\hline & & & ESTíMULO & $\cdot 1,0229 \quad-2,6152$ & 0,0050 \\
\hline
\end{tabular}

Em relação ao sinal esperado do coeficiente da variável explicativa, esses resultados demonstram que: (i) a média dos acertos declarados pelos respondentes que receberam o estímulo moral foi maior no caso dos alunos das instituições públicas, ao se considerarem todos os elementos pesquisados, o que é sinal contrário à premissa da pesquisa; (ii) essa situação é corrigida, porém, ao se excluírem os efeitos dos valores extremos; (iii) no caso das instituições privadas a média de acertos declarados pelos alunos submetidos ao estímulo moral é menor que a dos que não receberam o estímulo, quer sejam considerados todos os elementos da amostra ou excluídos os outliers.

Quanto à relevância estatística da variável ESTÍMULO $_{i}$ para explicar o nível de acertos declarados pelos respondentes, o $p$-valor apurado nas regressões demonstra a ausência de significância na relação entre as variáveis para os alunos das instituições públicas, enquanto no caso dos alunos das instituições privadas a variável independente é considerada significante para explicar o grau de acertos declarados. Essa evidência é confirmada tanto quando se considera a amostra completa como quando se retiram os outliers, sendo que a exclusão dos valores extremos resulta no aumento da significância estatística de $98,08 \%$ para $99,50 \%$.

Com isso, a hipótese nula de que o estímulo moral não repercute no comportamento dos agentes não pode ser rejeitada para o caso dos alunos das instituições públicas, mas é rejeitada com alto nível de confiança para o caso dos alunos das instituições privadas pesquisadas.

\subsection{Resultados por gênero}

Em relação à variável gênero, os resultados destacados na Tabela 6 demonstram que o estímulo moral não tem influência no comportamento dos alunos do sexo feminino, tendo em vista que a média dos acertos declarados pelos dois grupos - com e sem estímulo - não são estatisticamente diferentes, independentemente de se considerar a amostra completa ou a depurada com a exclusão dos outliers.

No caso dos alunos do sexo masculino, ao contrário, as evidências demonstram que há relação estatística relevante entre o nível declarado de acertos pelos pesquisados e o fato de os mesmos terem se submetido ao estímulo moral representado pela leitura do "juramento", tanto considerando a amostra completa como excluindo os outliers. Cabe ressaltar que a exclusão dos efeitos dos valores extremos aumentou o nível de confiança para rejeição da hipótese nula, passando de 93,25\% para 99,41\%, de acordo com o p-valor apurado nas regressões, aumentando a robustez das conclusões estatísticas. 
Tabela 6 - Resumo dos Testes do modelo (3.1) - Por Gênero

\begin{tabular}{|c|c|c|c|c|c|c|}
\hline \multicolumn{7}{|c|}{ Variável dependente: ACERTOS } \\
\hline \multicolumn{2}{|c|}{$\begin{array}{l}\text { Identificação do } \\
\text { segmento da amostra }\end{array}$} & $\begin{array}{c}\text { Tamanho } \\
\text { amostra }\end{array}$ & $\begin{array}{l}\text { Variável } \\
\text { independente }\end{array}$ & Coeficiente & Estatisticat & p-valor \\
\hline \multirow{4}{*}{ Masculino } & \multirow{2}{*}{ Amostra completa } & \multirow{2}{*}{157} & $C$ & 7,5658 & 27,6239 & 0,0000 \\
\hline & & & ESTÍMULO & $-0,5781$ & $-1,5162$ & 0,0657 \\
\hline & \multirow{2}{*}{ Excluindoutliers } & \multirow{2}{*}{147} & $C$ & 7,8857 & 30,9227 & 0,0000 \\
\hline & & & ESTÍMULO & $-0,8987$ & $-2,5506$ & 0,0059 \\
\hline \multirow{4}{*}{ Feminino } & \multirow{2}{*}{ Amostra completa } & \multirow{2}{*}{131} & $\bar{C}$ & 7,6232 & 31,4452 & 0,0000 \\
\hline & & & ESTíMULO & $-0,0264$ & $-0-0749$ & 0,4702 \\
\hline & \multirow{2}{*}{ Excluindouttiers } & \multirow{2}{*}{129} & C & 7,6912 & 32,9827 & 0,0000 \\
\hline & & & ESTÍMULO & $-0,0026$ & $-0,0078$ & 0,4969 \\
\hline
\end{tabular}

Em suma, os resultados apresentam conclusões distintas em relação ao efeito do estímulo, quando se considera a variável gênero, ou seja, a hipótese nula de que o estímulo moral não influencia o comportamento dos agentes não é rejeitada para o sexo feminino, mas é rejeitada no caso dos alunos do sexo masculino.

Cabe ressaltar que, no caso do gênero feminino, não obstante não haver relação significante entre o nível de acerto e o estímulo moral representado pelo juramento, o sinal do coeficiente da variável explicativa foi negativo, tanto se considerando a amostra completa quanto se excluindo os valores extremos, o que é coerente com as premissas do trabalho.

Como curiosidade, merece destaque o fato de que, ao se eliminar os valores extremos, a média de acertos declarados pelas mulheres dos grupos com e sem estímulo é exatamente igual,

7,69, o que dá a dimensão da não influência do estímulo moral no comportamento dos alunos do sexo feminino. Isso pode permitir dois tipos de conclusões: (i) as mulheres têm formação moral consolidada, não dependendo de um estímulo moral para declarar o verdadeiro nível de acerto; ou (ii) as mulheres não se deixam influenciar por estímulos morais eventuais, caso tenham interesse em fazer uma falsa declaração.

\subsection{Resultados por faixa etária}

Para avaliar a eventual diferença de comportamento em relação à variável faixa etária, a amostra foi segregada em subgrupos - até 20 anos, de 21 a 24 anos, de 25 a 30 anos e acima de 30 anos - procurando-se encontrar a diversidade nos estágios de maturidade dos respondentes. Os resultados demonstrados na Tabela 7 evidenciam que para os subgrupos de até 20 anos e de 21 a 24 anos não foram encontradas significâncias estatísticas entre o grau de acertos declarados pelos alunos e o recebimento do estímulo moral representado pela leitura do "juramento", independentemente de se considerar a amostra completa ou a depurada pela exclusão dos outliers.

Para os alunos na faixa de 25 a 30 anos, os resultados demonstram a influência do estímulo moral, tanto se considerando a amostra completa quanto se excluindo os valores extremos, sendo que neste último caso ocorre um aumento da significância estatística, passando de um nível de confiança de $92,20 \%$ para $98,07 \%$, de acordo com o p-valor apurado nas regressões.

Em relação à faixa etária acima de 30 anos, ao considerar a amostra completa, não se confirma o efeito do estímulo moral. Ao se depurar a amostra, com a exclusão dos valores extremos, a hipótese nula é rejeitada com um nível de confiança de $92,41 \%$, evidenciando a relação entre as variáveis dependente e independente.

Tabela 7 - Resumo dos Testes do modelo (3.1) - Por Faixa Etária

\begin{tabular}{|c|c|c|c|c|c|c|}
\hline \multicolumn{7}{|c|}{ Variável dependente: ACERTOS } \\
\hline \multicolumn{2}{|c|}{$\begin{array}{l}\text { Identificação do } \\
\text { segmento da amostra }\end{array}$} & $\begin{array}{l}\text { Tamanho } \\
\text { amostra }\end{array}$ & $\begin{array}{c}\text { Variável } \\
\text { independente }\end{array}$ & Coeficiente & Estatistica t & p-valor \\
\hline \multirow{4}{*}{ té 20 anos } & \multirow{2}{*}{ Amostra completa } & \multirow{2}{*}{105} & $\mathrm{C}$ & 7,9464 & 31,8882 & 0,0000 \\
\hline & & & ESTÍMULO & $-0,1301$ & $-0,3566$ & 0,3610 \\
\hline & \multirow{2}{*}{ Excluindooutliers } & \multirow{2}{*}{105} & $\mathrm{C}$ & 7,9464 & 31,8882 & 0,0000 \\
\hline & & & ESTÍMULO & $-0,1301$ & $-0,3566$ & 0,3610 \\
\hline \multirow{4}{*}{$\begin{array}{l}\text { De } 21 \text { a } \\
24 \text { anos }\end{array}$} & \multirow{2}{*}{ Amostra completa } & \multirow{2}{*}{81} & $\mathrm{C}$ & 7,5588 & 18,2891 & 0,0000 \\
\hline & & & ESTÍMUL0 & $-0,3248$ & $-0,5986$ & 0,2756 \\
\hline & \multirow{2}{*}{ Excluindooutliers } & \multirow{2}{*}{76} & $\mathrm{C}$ & 7,6970 & 20,9471 & 0,0000 \\
\hline & & & ESTÍMULO & $-0,2086$ & $-0,4270$ & 0,3353 \\
\hline \multirow{4}{*}{$\begin{array}{l}\text { De } 25 \text { a } \\
30 \text { anos }\end{array}$} & \multirow{2}{*}{ Amostra completa } & \multirow{2}{*}{53} & $\mathrm{C}$ & 7,5714 & 17,8025 & 0,0000 \\
\hline & & & ESTÍMUL0 & $-0,8914$ & $-1,4395$ & 0,0780 \\
\hline & \multirow{2}{*}{ Excluindooutliers } & \multirow{2}{*}{51} & $\mathrm{C}$ & 7,9231 & 19,3641 & 0,0000 \\
\hline & & & ESTÍMULO & $-1,2431$ & $-2,1271$ & 0,0193 \\
\hline \multirow{4}{*}{$\begin{array}{l}\text { Acima de } \\
30 \text { anos }\end{array}$} & \multirow{2}{*}{ Amostra completa } & \multirow{2}{*}{48} & $\mathrm{C}$ & 6,8461 & 13,8994 & 0,0000 \\
\hline & & & ESTÍMUL0 & $-0,1643$ & $-0,2259$ & 0,4111 \\
\hline & \multirow{2}{*}{ Excluindooutliers } & \multirow{2}{*}{44} & $\mathrm{C}$ & 7,3913 & 16,2189 & 0,0000 \\
\hline & & & ESTÍMUL0 & $-0,9627$ & $-1,4594$ & 0,0759 \\
\hline
\end{tabular}

Os resultados apurados segregando-se a amostra por faixa etária demonstram que os efeitos do estímulo moral no 
comportamento dos alunos pesquisados se materializam entre aqueles que podem ser definidos como "fora de faixa", ou seja, que não concluíram o curso dentro do período regular de formação - até 24 anos, considerandose o tempo desde o ingresso no ensino fundamental à conclusão do curso superior - ou que ingressaram no curso depois de vivência profissional. Em resumo, a hipótese nula de que o estímulo moral não influencia o comportamento dos agentes não é rejeitada para as faixas etárias até 24 anos, mas é rejeitada com nível de confiança entre $98,07 \%$ e $92,41 \%$ para as faixas de 25 a 30 anos e acima de 30 anos, respectivamente.

\subsection{Resultados por estágio no curso}

Para examinar o comportamento dos alunos em relação ao seu estágio no curso, a amostra foi segregada em três subgrupos - até $4^{\circ}$ semestre, $5^{\circ}$ e $6^{\circ}$ semestres e a partir do $7^{\circ}$ semestre - de forma a refletir segmentos representativos da parte inicial do curso, dos semestres intermediários e dos estágios finais do curso.

Os resultados destacados na Tabela 8 demonstram que o efeito da leitura do "juramento" é relevante para explicar o grau de acertos declarados pelos alunos que cursam até o $4^{\circ}$ semestre, com um nível de confiança de $93,74 \%$, independentemente de se considerar a amostra completa ou a ajustada com a exclusão dos outliers, de acordo com o $p$-valor apurado nas regressões. Para os alunos do $5^{\circ}$ e do $6^{\mathrm{o}}$ semestres, a rejeição da hipótese nula só seria possível com a exclusão dos efeitos dos valores extremos e com um nível de confiança de 89,82\%.

Para os alunos que estão nos estágios finais do curso, a partir do $7^{\circ}$ semestre, não foram encontradas evidências de relevância estatística entre o estímulo moral representado pelo "juramento" e o nível de acertos declarados pelos respondentes. De qualquer forma, cabe ressaltar o fato de que a depuração da amostra, com a exclusão dos valores extremos, corrigiu a contradição verificada na amostra completa nesse subgrupo, quando os alunos que receberam o estímulo moral tinham apresentado uma média de acertos superior (embora não relevante estatisticamente) à dos alunos que leram o texto "neutro". Com a eliminação dos efeitos dos outliers, embora as médias dos dois grupos não possam ser consideradas estatisticamente diferentes, é apresentado um sinal coerente com a premissa do trabalho, ou seja, o nível de acertos informado pelos alunos que receberam o estímulo é menor que o indicado por aqueles que não receberam o estímulo moral.

Como síntese dos resultados apurados de acordo com o estágio dos alunos no curso, pode-se afirmar que a hipótese nula de que o estímulo moral não influencia o comportamento dos agentes é rejeitada para aqueles que estão na fase inicial do curso (até o $4^{\circ}$ semestre) com nível de confiança de $93,74 \%$, enquanto para os níveis intermediários $\left(5^{\circ}\right.$ e $6^{\circ}$ semestre $)$ essa rejeição conta com um nível de confiança de $89,82 \%$. Para os que cursam os semestres finais do curso, embora os resultados apresentem o sinal esperado - média menor de acertos dos alunos que leram o "juramento" -, a diferença não é estatisticamente relevante.

Tabela 8 - Resumo dos Testes do modelo (3.1) - Por Estágio no Curso

\begin{tabular}{|c|c|c|c|c|}
\hline \multirow{2}{*}{ Identificaçào da amostra } & \multicolumn{3}{|c|}{ Média do nivel de acertos } & \multirow{2}{*}{$\begin{array}{l}\text { Ordempor } \\
\text { differenç̧a }\end{array}$} \\
\hline & Com estimulo & Sem estimulo & Diferenca & \\
\hline Amostra completa & 7.25 & 7.58 & .0 .33 & 70 \\
\hline Excluindo outliers & 7.30 & 7.79 & .0 .49 & $6^{0}$ \\
\hline Amostra completa & 7.64 & 8.47 & .0 .83 & $3^{0}$ \\
\hline Excluindo outliers & 7.74 & 8.35 & $\cdot 0.01$ & $4^{0}$ \\
\hline Adicional Amostra completa & 7.60 & 9.00 & .1 .40 & 10 \\
\hline com" coelho" Excluindo outliers & 7.60 & 8.68 & $\cdot 1.08$ & $2^{0}$ \\
\hline \multirow{2}{*}{$\begin{array}{l}\text { Adicional Amostra completa } \\
\text { sem "coelho" Excluindo outliers }\end{array}$} & 7.67 & 8.17 & .0 .50 & 50 \\
\hline & 7.84 & 8.15 & .0 .31 & $8^{0}$ \\
\hline
\end{tabular}

Em resumo, os testes adicionais reforçaram as conclusões de que a variável é relevante para explicar o nível de acertos declarados pelos alunos, demonstrando ser útil para reduzir o risco moral relacionado e que uma premiação mais seletiva e atraente aumenta a relevância na reação comportamental dos pesquisados.

\section{CONCLUSÃO}

O propósito do presente estudo foi avaliar, com base na estrutura conceitual do modelo principal-agente, se o estímulo moral, representado pela leitura do "juramento" realizado pelos formandos de Ciências Contábeis, era 
capaz de influenciar no comportamento ético dos estudantes. Os resultados do experimento corroboram as premissas da pesquisa, rejeitando-se a hipótese nula de que esse estímulo não influencia no padrão de respostas dos alunos pesquisados, cabendo ressaltar que, retirando os efeitos dos valores extremos, os outliers, as conclusões estatísticas se mostraram mais robustas. Em suma, os testes demonstraram que os participantes submetidos ao estímulo moral declararam uma média de acertos inferior ao declarado por aqueles que não receberam o estímulo. A análise de segmentos da amostra demonstrou, adicionalmente, que esse efeito foi mais evidente nos estudantes de instituições privadas, do sexo masculino, com idade superior a 25 anos e que estão cursando até o $4^{\circ}$ semestre. Ao se alterar o padrão de incentivo por nível de acerto, ficou evidenciado, também, que uma premiação mais atraente altera o comportamento dos alunos, em particular dos que não foram submetidos ao estímulo moral, aumentando o peso dos valores extremos, os outliers. As evidências empíricas do estudo revelam que os estímulos morais podem influenciar no funcionamento do modelo principal-agente, ou seja, que as respostas do agente podem ser modificadas em função dos estímulos morais que ele receba. Além do mais, revela que fatores comportamentais interferem nas respostas dos agentes, confirmando as premissas de estudos como os que dão sustentação às finanças comportamentais.

Do ponto de vista mais prático e objetivo, a corroboração das premissas do estudo, com a rejeição da hipótese nula, é um indício de que uma forma de criar condições para a redução do risco moral decorrente da atuação de contadores e auditores em desacordo com os padrões de comportamento esperados pela profissão pode ser apostar na incorporação, na grade curricular dos cursos de Ciências Contábeis, de disciplinas que reforcem a formação moral dos estudantes, o que pode contribuir para um ambiente profissional mais ético.

Por fim, cabe destacar, como limitação às conclusões do presente estudo, o fato de que a forma de seleção das turmas que participaram da pesquisa, que dependeu fundamentalmente da oportunidade de acesso pelos pesquisadores, não se observando o rigor estatístico de aleatoriedade da amostra, não permite que sejam formuladas inferências para o conjunto dos alunos de Ciências Contábeis do País, de uma região ou mesmo das cidades pesquisadas.

Gráfico 1 - Síntese das Diferenças de Médias entre os Grupos “Com” e "Sem” Estímulo para os Diversos Segmentos da Amostra

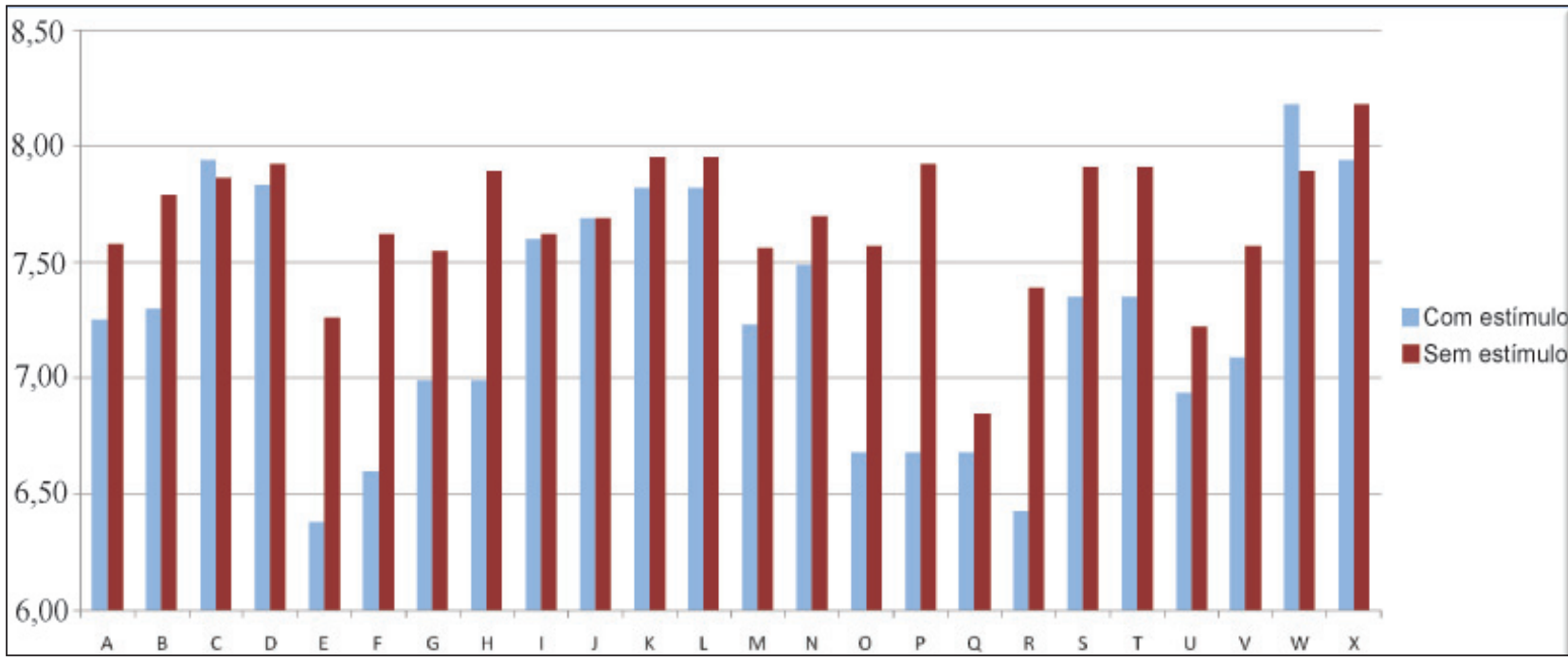

Legenda: (A) conjunto da amostra completa; (B) conjunto da amostra sem outliers; (C) instituições públicas completa; (D) instituições privadas sem outliers; (E) instituições privadas completa; (F) instituições privadas sem outliers; (G) masculino completa; (H) masculino sem outliers; (I) feminino completa; (J) feminino sem outliers; (K) até 20 anos completa; (L) até 20 anos sem outliers; (M) de 21 a 24 anos completa; (N) de 21 a 24 anos sem outliers; (O) de 25 a 30 anos completa; (P) de 25 a 30 anos sem outliers; (Q) acima de 30 anos completa; (R) acima de 30 anos sem outliers; (S) até $4^{\circ}$ semestre completa; (T) até $4^{\circ}$ semestre sem outliers; (U) $5^{\circ}$ e $6^{\circ}$ semestres completa; (V) $5^{\circ}$ e $6^{\circ}$ semestres sem outliers; (W) a partir do $7^{\circ}$ semestre completa; (X) a partir do $7^{\circ}$ semestre sem outliers. 


\section{REFERÊNCIAS}

ARIELY, Dan. Previsivelmente irracional: como as situações do dia-a-dia influenciam as nossas decisões. Rio de Janeiro: Campus, 2008.

BROOKS, Chris. Introductory econometrics for finance. Cambridge: Cambridge University Press, 2008.

EISENHARDT, Kathleen M. Agency theory: an assessment and review. Academy of Management Review, v. 1, p. 57-74, 1989.

HOLMSTROM, Bengt. Moral Hazard and observability. The Bell Journal of Economics, v. 10, n. 1, (Spring, 1979).

JENSEN, Michael; MECKLING, William. Theory of the firm: managerial behavior, agency costs and ownership structure. Journal of Financial Economics, v. 3, n. 4, p. 305-360, October 1976.

KIMURA, Herberto. Aspectos comportamentais associados às reações no mercado de capitais. RAEeletrônica, jan-jun, 2003.

KUHN, Thomas S. A Estrutura das Revoluções Científicas. São Paulo: Perspectiva, 1975.

LAMBERT, Richard A. Handbook of Management accounting Research. Amsterdan: Elsevir, 2007.

LIMA, Murillo Valverde. Um estudo sobre finanças comportamentais. RAE-eletrônica, p.6, jan-jun, 2003.

MACEDO JUNIOR.; et al. Prospect theory: A study of the endowment effect. Revista Contemporânea de Contabilidade, p.11-28, jul-dez, 2007.

MACIEIRA, Leonardo dos Santos. Risco Moral no cálculo do reposicionamento tarifário: o problema do oportunismo das distribuidoras de energia elétrica. Dissertação de Mestrado, Programa de Pós-Graduação em Administração da USP, 2006.

MILLER, George A.; GALANTER Eugene; PRIBRAM, Karl H. Plans and the structure of behavior. New York:
Henry Holt, 1960.

NEWELL, A., SHAW, J. C., \& SIMON, H. A. Elements of a theory of human problem solving. Psychological Review, v. 65, p. 151-166, 1958.

SOBREIRA, Marcelo de Souza. Aplicação da teoria do prospecto nos bancos brasileiros:agregando valor para a carteira de investimentos de um fundo de pensão. Dissertação de Mestrado, Programa de PósGraduação em Administração do IBMEC, 2007.

STEVENS, Douglas E.; THEVARANJAN, Alex. A moral solution to the moral hazard problem. Accounting, Organizations and Society, v. 35, n. 1, p. 125-139, January 2010.

THEÓPHILO, Carlos Renato. Algumas reflexões sobre pesquisas empíricas em Contabilidade. Caderno de Estudo, São Paulo, FIPECAFI, v. 10, nº 19, p. 9-15, setembro/dezembro, 1998. 